\title{
Targeted Temperature Management in Pediatric Central Nervous System Disease
}

\author{
Robert Newmyer, MD \\ Jenny Mendelson, MD \\ Diana Pang, MD \\ Ericka L. Fink, $M D, M S^{*}$
}

\author{
Address \\ "Division of Pediatric Critical Care Medicine, Children's Hospital of Pittsburgh of \\ UPMC, 4401 Penn Avenue, Faculty Pavilion, 2nd floor, Pittsburgh, PA 15224, USA \\ Email: finkel@ccm.upmc.edu
}

Published online: 28 January 2015

(C) Springer International Publishing AG 2015

This article is part of the Topical Collection on Pediatric Critical Care Medicine

Keywords Pediatric - Hypothermia - Neurocritical care - Targeted temperature management - Brain disease

\section{Opinion statement}

Acute central nervous system conditions due to hypoxic-ischemic encephalopathy, traumatic brain injury (TBI), status epilepticus, and central nervous system infection/inflammation are a leading cause of death and disability in childhood. There is a critical need for effective neuroprotective therapies to improve outcome targeting distinct disease pathology. Fever, defined as patient temperature $>38{ }^{\circ} \mathrm{C}$, has been clearly shown to exacerbate brain injury. Therapeutic hypothermia $(\mathrm{HT})$ is an intervention using targeted temperature management that has multiple mechanisms of action and robust evidence of efficacy in multiple experimental models of brain injury. Prospective clinical evidence for its neuroprotective efficacy exists in narrowly defined populations with hypoxic-ischemic injury outside of the pediatric age range while trials comparing hypothermia to normothermia after TBI have failed to demonstrate a benefit on outcome but consistently demonstrate potential use in decreasing refractory intracranial pressure. Data in children from prospective, randomized controlled trials using different strategies of targeted temperature management for various outcomes are few, but a large study examining HT versus controlled normothermia to improve neurological outcome in cardiac arrest is underway. 


\section{Targeted Temperature Management in Pediatric Central Nervous System Conditions}

Acute pediatric central nervous system (CNS) conditions, including hypoxic-ischemic encephalopathy (HIE) from cardiac arrest, traumatic brain injury (TBI), status epilepticus, and infection/inflammation are a leading cause of morbidity and mortality worldwide [1-3]. Morbidities commonly affect multiple patient and family domains-cognition, motor function, emotional health, and quality of life-and are often life-long [4-9]. There is a dearth of efficacious therapies shown to improve neurological outcome, and despite the publication of treatment guidelines, care is largely supportive $[10 \bullet, 11,12]$.

Fever $\left(>38^{\circ} \mathrm{C}\right)$ early after CNS insult can have lasting detrimental effects on outcome [13•, 14-17]. Hypothermia (HT) is thought to have promising potential as a neuroprotective therapy due to its multiple mechanisms of action that involve amelioration of excitotoxicity, oxidative stress, caspase activation, mitochondrial dysfunction, membrane ion flux, and ultimately cell death $[18,19]$. HT improved histological and functional outcomes in multiple experimental models of brain ischemia and trauma. HT provided neuroprotection in a dose-dependent manner in models of hypoxiaischemia [20-22]. Similar neuroprotection was found in trauma models, but when secondary insults such as hypoxia and hypotension accompanied the traumatic insult, benefits were frequently lost [23-25].

In the past decade, randomized, clinical trials (RCTs) have led to HT being implemented as standard of care in neonates with moderate-severe birth asphyxia and in adults remaining comatose following witnessed arrhythmia-induced cardiac arrest [26-28]. In pediatric brain disease, HT has had mixed results thus far (Table 1) $[29,30 \bullet \bullet, 31 \bullet \bullet]$.

Critics have pointed out that previous landmark RCTs did not actively maintain normothermia in the control or normothermia arm, with many subjects in the normothermia arm having fever, possibly explaining the superior performance of HT [32•, 33]. Targeted Temperature Management (TTM) is a term describing focused monitoring and tightly controlled manipulation of patient temperature, encompassing both actively controlled normothermia and induced HT [28]. New data showing similar outcomes with either actively controlled normothermia or induced HT among adults surviving cardiac arrest raised fresh questions about best practices after resuscitation. The primary advantages of controlled normothermia versus HT are largely safety-related, as both require substantial resources, monitoring, and supportive care [34].

\section{Cardiac arrest}

Fever is common after pediatric cardiac arrest and is associated with decreased survival and unfavorable neurological outcomes [15, 35]. Therapeutic HT has been proposed as a potential post-resuscitation neuroprotective therapy for children after notable recoveries occurred in cold-water drowning patients in the 1970s [36, 37]. Landmark adult and neonatal studies led to the adoption of HT for these populations $\left(32^{\circ}-34^{\circ} \mathrm{C}\right.$ for 12 or 24 and $72 \mathrm{~h}$, respectively) [26, 38-42]. New data suggests that TTM, a strategy of active prevention of fever $\left(36^{\circ} \mathrm{C}\right)$, performed equivalently to HT in adults with cardiac arrest [32•].

In children, two retrospective observational studies showed no difference in hospital mortality between patients who received or did not receive therapeutic HT $[43 \bullet, 44 \bullet]$. It is notable that HT was not protocolized in terms of patient eligibility, time to target temperature, target temperature choice, duration of therapy, or rewarming schedule in either study. Children who were cooled were noted to be sicker than those who were not cooled prior to induction in terms of having had longer duration of pulselessness and more unwitnessed out-ofhospital events. Children in whom HT was applied required more frequent electrolyte replacement and received more insulin infusions than non-HT 


\section{Table 1. Recommendation for clinical use of HT and level of evidence}

Recommendation for clinical use of HT

Cardiac arrest

Status epilepticus

Traumatic brain injury

CNS inflammation out-of-hospital VF cardiac arrest.
1. Therapeutic HT $\left(32{ }^{\circ} \mathrm{C}\right.$ to $\left.34^{\circ} \mathrm{C}\right)$ may be considered for children who remain comatose after resuscitation from cardiac arrest.

2. It is reasonable for adolescents resuscitated from sudden, witnessed,

3. Monitor temperature continuously, if possible, and treat fever $\left(38^{\circ} \mathrm{C}\right)$ aggressively with antipyretics and cooling devices because fever adversely influences recovery fromischemic brain injury.

1. Case reports and animal data suggest that HT may assist with refractory seizure termination. No current recommendation for clinical use.

1. RCT data suggests a role for efficacy of HT decreasing intracranial pressure.

2. RCT data suggest not helpful, but a possible harmful role, of HT.

1. European Federation of Neurologic Societies (EFNS) guidelines on the management of community-acquired bacterial meningitis in older children and adults briefly mention normothermia or moderate hypothermia as an adjunctive therapy 77
Level of evidence

Class IIb, LOE C

Class IIa, LOE C

Class IIa, LOE C

Class IIb, LOE C

Class III, LOE A

Class III, LOE

Class I: Evidence or general agreement that a procedure or treatment is useful and effective

Class II: Conflicting evidence or divergence of opinion exists

Class IIa: Weight of evidence or opinion favors utility or efficacy

Class IIb: Weight of evidence or opinion is less well established

Class III: Evidence or general agreement that the procedure or treatment is either not useful or effective or in some cases may be harmful

LOE A: Data derived from multiple randomized clinical trials

LOE B: Data derived from a single randomized clinical trial

LOE C: Consensus expert opinion

patients. Additionally, children with temperatures below the lower end of the target temperature range $\left(<32{ }^{\circ} \mathrm{C}\right)$ had higher mortality, postulated to be due to poikilothermia secondary to severe HIE. A recent Cochrane systematic review concluded that there was "no evidence from RCTs to support or refute the use of therapeutic $\mathrm{HT}^{\prime \prime}$ after pediatric cardiac arrest [45]. In children with cardiac arrest, the 2010 International Liaison Committee on Resuscitation (ILCOR) Pediatric Task Force statement recommended that "Therapeutic HT $\left(32{ }^{\circ} \mathrm{C}\right.$ to $\left.34{ }^{\circ} \mathrm{C}\right)$ may be considered for infants and children who remain comatose following resuscitation from cardiac arrest" [12].

To date, no prospective RCT of HT after pediatric cardiac arrest has been published, although results from the Therapeutic Hypothermia after Pediatric Cardiac Arrest (THAPCA), a large international trial that separately examines HT versus controlled normothermia after out-of-hospital and in-hospital pediatric cardiac arrest, is highly anticipated [33]. Detailed recommendations from ILCOR on implementing TTM and HT are lacking, but some publications offer guidance $[46,47]$.

\section{Status epilepticus}

Fever is associated with increased risk of seizures in susceptible children [48, 49]. HT has been shown to decrease seizure frequency and duration in experimental models of status epilepticus [50, 51]. In an early case series (five adults 
and one child), TTM $\left(31-36.5^{\circ} \mathrm{C}\right)$, when used as an adjunct to antiepileptic medications, successfully terminated status epilepticus [51].

The mechanism underlying the antiepileptic effect of HT remains unclear, but hypotheses include alteration of postsynaptic voltage-gated channels, disturbance of membrane polarity via ion pumps, and reduction of presynaptic excitatory transmitter release [52-57]. Interestingly, the antiepileptic effects of commonly used medications such as benzodiazepines can be potentiated by adjunctive HT via decreased blood-brain barrier permeability leading to increased intracerebral drug concentrations [58].

In a contemporary case series of four adults with status epilepticus, endovascular HT $\left(31-35^{\circ} \mathrm{C}\right)$ was used in addition to midazolam and/or pentobarbital infusions [59]. Seizures were successfully aborted during treatment but returned in two patients post-rewarming. One patient death due to sepsis was thought to have been influenced by the combined immunosuppressive effect of HT and pentobarbital. No prospective comparative data exist regarding the use of controlled normothermia or HT in pediatric status epilepticus, but cases are informative. An infant treated with controlled normothermia $\left(36^{\circ} \mathrm{C}\right)$ for 4 days resulted in marked reduction of seizure frequency and decrease of intravenous antiepileptic dosing [60•]. An older series of three children were treated with HT $\left(30-31^{\circ} \mathrm{C}\right)$ and concurrent barbiturate therapy for 2-5 days with resultant termination of seizures [61]. Guilliams et al. included five children with refractory status epilepticus due to varying diagnoses in which HT was applied. Temperatures were maintained $32-35{ }^{\circ} \mathrm{C}$ for $24-$ $120 \mathrm{~h}$ with varying rewarming approaches to successfully terminate seizures $[62 \bullet \bullet]$. Three patient deaths were attributed to underlying disease. Three surviving patients had mild cognitive, functional, and/or behavioral deficits noted. Serious adverse events included sepsis $(n=1)$, lactic acidosis $(n=2)$, and hypokalemia $(n=3)$. In a recent case report, HT to $33-34{ }^{\circ} \mathrm{C}$ in a 4 -month-old child with malignant migrating partial seizures of infancy and SCN1A had success in terminating status epilepticus during HT, but seizures recurred post-rewarming $[63 \bullet]$.

Guidelines for the treatment of status epilepticus in adults were published by the Neurocritical Care Society (NCS) in 2012, and two pediatric centers have published their treatment protocols without specifying a definitive role for HT [64-66]. The NCS guidelines remark HT to be an emerging therapy "with limited data on the safety and effectiveness of these treatments for refractory status epilepticus" and therefore "recommend to reserve these therapies to patients who do not respond to refractory status epilepticus antiepileptic drug treatment." A recent review by the Pediatric Status Epilepticus Research Group notes HT to be an emerging therapy for refractory status epilepticus but makes no treatment recommendation [67].

\section{Traumatic brain injury}

Fever after TBI exacerbates brain injury and worsens outcome $[68,69,16,70]$. Studies in rat models of TBI suggested that HT is neuroprotective [71, 72]. Neuroprotective mechanisms of action of HT noted in experimental models include decreased brain metabolism, attenuation of proinflammatory cytokines, decrease in free radical production, decrease in toxic metabolites and 
excitatory substances, prevention of apoptosis, and preservation of high-energy phosphates and mitochondrial dysfunction [27, 73-75]. Therapeutic HT has been trialed in patients both as a treatment for refractory intracranial hypertension and to improve neurological outcome in the setting of severe (GCS score $\leq 8)$ TBI.

Four RCTs have been performed in children with severe TBI to evaluate HT $\left(32-34.5^{\circ} \mathrm{C}\right)$ versus controlled normothermia for effect on outcome $[30 \bullet \bullet, 31 \bullet \bullet, 76 \bullet, 77 \bullet \bullet]$. In a small RCT $(n=21)$, HT was effective in decreasing ICP as an adjunct to standard treatment [76•]. Adelson et al. phase II RCT $(n=75)$ reported that $48 \mathrm{~h}$ of HT could be performed safely and reduced ICP compared with children in the normothermia group. Rebound intracranial hypertension was occasionally

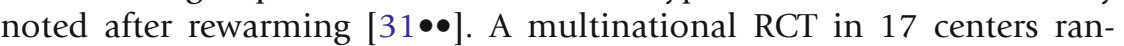
domized 225 children to HT or normothermia for $24 \mathrm{~h}$ and rewarmed at $0.5 \mathrm{C}$ per hour $[30 \bullet \bullet]$. HT conveyed no functional outcome or mortality benefit at 6 -month post-TBI. Instead, there was a trend toward increased mortality in the HT versus normothermia group $(p=0.06)$. HT was also effective in decreasing ICP in this study, but rebound hypotension (and decreased cerebral perfusion pressure) requiring vasoactive support in the rewarming period occurred more frequently in the HT group than in the normothermia group. Most recently, the Cool Kids Trial, a phase III multinational 15 center RCT, randomized 77 children to HT or normothermia for $48-72 \mathrm{~h}$ followed by rewarming at a relatively slow rate of $0.5-1{ }^{\circ} \mathrm{C}$ over $12-24 \mathrm{~h}[77 \bullet \bullet]$. The study was terminated for futility on interim analysis without a difference in outcome or adverse events between treatment groups.

Chapter 9 in the pediatric guidelines for severe TBI makes distinct recommendations for the use of HT to treat of refractory hypertension and to improve neurological outcome. First, the guidelines provide level II evidence for recommending moderate $\mathrm{HT}\left(32-33^{\circ} \mathrm{C}\right)$ to treat refractory intracranial hypertension for a duration of up to $48 \mathrm{~h}$, followed by rewarming relatively slowly to prevent rebound intracranial hypertension $\left(0.5-1{ }^{\circ} \mathrm{C}\right)$ over $12-24 \mathrm{~h} \mathrm{[10 \bullet ].}$ Next, the guidelines make a level II recommendation for avoidance of moderate HT $\left(32-33^{\circ} \mathrm{C}\right)$ initiated early after severe TBI for neuroprotection followed by a rewarming of $0.5^{\circ} \mathrm{C} / \mathrm{h}$. A level III recommendation was made for the early administration of HT for 48-h duration with slow rewarming (no faster than $0.5 \mathrm{C}$ every $3-4 \mathrm{~h}$ ) as a neuroprotective strategy.

\section{CNS infection/inflammation}

Neither controlled normothermia nor HT is a standard treatment for pediatric CNS infection/inflammation, which encompasses infectious encephalitis, postinfectious encephalitis, and bacterial meningitis. However, case reports and series indicate that HT has been used to treat various viral and post-viral CNS pathologies.

Rationale for using TTM in CNS infection and inflammatory disease is to mitigate cytokine-mediated inflammation that may be exacerbated by fever and sepsis. In a case-control study by Ichiyama et al., inflammatory markers, including interleukin (IL)-6, IL-10, soluble tumor necrosis factor receptor 1 
(sTNFR1) were increased in the serum and cerebrospinal fluid (CSF) of 13 children with viral syndromes complicated by fever, acute encephalopathy, RSE, and poor outcome [78].

Kawano et al. performed a retrospective observational study of 43 children with acute viral encephalitis complicated by acute necrotizing encephalopathy, hemorrhagic shock and encephalopathy syndrome, or acute encephalopathy with refractory seizures. Children underwent HT (33.5-35 $\left.{ }^{\circ} \mathrm{C}\right)$ or normothermia [79•]. Duration of HT was between 48 and $72 \mathrm{~h}$, and management of fevers in the normothermia group was not described. Children who underwent HT within $12 \mathrm{~h}$ of presentation had better Pediatric Cerebral Performance Category (PCPC) scores compared to those who were kept normothermic. PCPC scores were worse in children with HT initiated at greater than $12 \mathrm{~h}$ following presentation.

Two case reports describe the use of HT in encephalitis. A previously healthy 4-year-old female with influenza A complicated by acute necrotizing encephalopathy presented with tonic posturing and seizure without cerebral edema [80]. HT $\left(34^{\circ} \mathrm{C}\right)$ was initiated on the 6th day of illness and was maintained for a predetermined duration of 2 days. She also received methylprednisolone and intravenous immunoglobulin (IVIG), although the timing of these medications in relation to HT was not described. At a 7-month follow-up visit, the patient lacked cognitive deficits but had a persistent intention tremor. Another case report described a 3-year-old Japanese boy with acute demyelinating encephalomyelitis (ADEM) due to mumps [81]. Despite completing high-dose corticosteroid therapy, he developed decerebrate posturing and severe cerebral edema and uncal herniation on CT on the 4 th day of illness. HT $\left(34^{\circ} \mathrm{C}\right)$ was initiated and maintained for 6 days, with concurrent with IVIG and repeat corticosteroid therapy provided. Indications for rewarming were not reported. At 52 days, the patient also had a mild intention tremor. All patients in these reports received appropriate antiviral (e.g., oseltamivir and/or acyclovir) and antibiotic medications and some received antiepileptic drug treatment. Complications of HT were similar to those of studies in other studies, including hypotension, hypokalemia, hyperglycemia, and coagulopathy.

There are no reports of HT used in pediatric patients with bacterial meningitis. However, a recent RCT compared HT $\left(32-34{ }^{\circ} \mathrm{C}\right)$ for $48 \mathrm{~h}$ versus passive normothermia in 98 adults with bacterial meningitis. The study was stopped early as patients in the HT group had higher mortality than patients in the normothermia group (51 vs $31 \%, p=0.04$ ) [82••].

Although there are comprehensive guidelines for the diagnosis and treatment of pediatric encephalitis and meningitis, TTM, including fever control and HT, is only briefly mentioned in Chaudhuri et al. for consideration as an adjunctive therapy in bacterial meningitis [83-85]. Recommendations for antiinflammatory management do include corticosteroids, IVIG, and plasmapheresis.

Fever occurring in the early period of pediatric brain disease is associated with worse outcome. Continuous temperature monitoring in the acute treatment period and active prevention of fever in critically ill children with CNS disease 
may therefore be vital components of neurocritical care support. Despite efficacy in various experimental models of brain disease, therapeutic HT has thus far demonstrated limited utility in pediatrics, but important RCTs utilizing TTM in pediatric cardiac arrest are pending.

\section{Compliance with Ethics Guidelines}

\section{Conflict of Interest}

Robert Newmyer, Jenny Mendelson, and Diana Pang declare that they have no conflict of interest.

Ericka Fink declares the following research grants: NIH 1K23 NS065132 and U01 HL094345, and PCORI CER1310-08343.

Human and Animal Rights and Informed Consent

This article does not contain any studies with human or animal subjects performed by any of the authors.

\section{References and Recommended Reading}

Papers of particular interest, published recently, have been highlighted as:

- Of importance

-• Of major importance

1. Au AK, Carcillo JA, Clark RSB, Bell MJ. Brain injuries and neurological system failure are the most common proximate cause of death in children admitted to a pediatric intensive care unit. Pediatr Crit Care Med. 2011;12:566-71.

2. Fink EL, Tasker RC, Beca J, et al. Prevalence of acute critical neurological disease in children: a global epidemiological assessment (PANGEA). Crit Care Med. 2013;17 Suppl 2:346.

3. Moreau JF, Fink EL, Hartman ME, et al. Hospitalizations of Children With Neurological Disorders in the United States. Pediatr Crit Care Med 2013.

4. Knoester H, Bronner MB, Bos AP. Surviving pediatric intensive care: physical outcome after 3 months. Intensive Care Med. 2008;34:1076-82.

5. Knoester $\mathrm{H}$, Bronner MB, Bos AP, Grootenhuis MA. Quality of life in children three and nine months after discharge from a paediatric intensive care unit: a prospective cohort study. Health Qual Life Outcomes. 2008;6:21.

6. Shi J, Xiang H, Wheeler K, et al. Costs, mortality likelihood and outcomes of hospitalized US children with traumatic brain injuries. Brain Inj. 2009;23:602-11.

7. Gilbert DL, Glauser TA. Complications and costs of treatment of refractory generalized convulsive status epilepticus in children. J Child Neurol. 1999;14:597601.

8. Aitken ME, McCarthy ML, Slomine BS, et al. Family burden after traumatic brain injury in children. Pediatrics. 2009;123:199-206.
9. Heindl UT, Laub MC. Outcome of persistent vegetative state following hypoxic or traumatic brain injury in children and adolescents. Neuropediatrics. 1996;27:94-100.

10. Kochanek PM, Carney N, Adelson PD, et al. Guidelines for the acute medical management of severe traumatic brain injury in infants, children, and adolescents-second edition. Pediatr Crit Care Med. 2012;13 Suppl $1: \mathrm{S} 1-82$

Chapter 9 provides guidelines for the use of hypothermia as secondary therapy for refractory intracranial hypertension and for neuroprotection.

11. Roach ES, Golomb MR, Adams R, et al. Management of stroke in infants and children: a scientific statement from a Special Writing Group of the American Heart Association Stroke Council and the Council on Cardiovascular Disease in the Young. Stroke.

2008;39:2644-91.

12. Kleinman ME, Chameides L, Schexnayder SM, et al. Part 14: pediatric advanced life support: 2010 American Heart Association Guidelines for Cardiopulmonary Resuscitation and Emergency Cardiovascular Care. Circulation. 2010;122:S876-908.

13. Bembea MM, Nadkarni VM, Diener-West M, et al. Temperature patterns in the early postresuscitation period after pediatric inhospital cardiac arrest. Pediatr Crit Care Med. 2010;11:723-30.

Persistent fever $\geq 38^{\circ} \mathrm{C}$ in the first $24 \mathrm{~h}$ after return of circulation was common $\mathrm{i}$ in a multicenter registry of in-hospital pediatric cardiac arrest, and was associated with unfavorable neurologic outcome. 
14. Greer DM, Funk SE, Reaven NL, Ouzounelli M, Uman GC. Impact of fever on outcome in patients with stroke and neurologic injury: a comprehensive meta-analysis. Stroke. 2008;39:3029-35.

15. Laptook A, Tyson J, Shankaran S, et al. Elevated temperature after hypoxic-ischemic encephalopathy: risk factor for adverse outcomes. Pediatrics. 2008;122:491-9.

16. Natale JE, Joseph JG, Helfaer MA, Shaffner DH. Early hyperthermia after traumatic brain injury in children: risk factors, influence on length of stay, and effect on short-term neurologic status. Crit Care Med. 2000;28:2608-15.

17. Zeiner A, Holzer M, Sterz F, et al. Hyperthermia after cardiac arrest is associated with an unfavorable neurologic outcome. Arch Intern Med. 2001;161:2007-12.

18. Polderman KH. Application of therapeutic hypothermia in the ICU: opportunities and pitfalls of a promising treatment modality. Part 1: Indications and evidence. Intensive Care Med. 2004;30:556-75.

19. Kochanek PM, Fink EL, Bell MJ, Bayir H, Clark RS. Therapeutic hypothermia: applications in pediatric cardiac arrest. J Neurotrauma. 2009;26:421-7.

20. Busto R, Dietrich WD, Globus MY, Valdes I, Scheinberg $P$, Ginsberg MD. Small differences in intraischemic brain temperature critically determine the extent of ischemic neuronal injury. J Cereb Blood Flow Metab. 1987;7:729-38.

21. Fink EL, Marco CD, Donovan HA, et al. Brief induced hypothermia improves outcome after asphyxial cardiopulmonary arrest in juvenile rats. Dev Neurosci. 2005;27:191-9.

22. Colbourne F, Corbett D. Delayed postischemic hypothermia: A six-month survival study using behavioral and histological assessments of neuroprotection. J Neurosci. 1995; 15:7250.

23. Bramlett HM, Green EJ, Dietrich WD, Busto R, Globus MY, Ginsberg MD. Posttraumatic brain hypothermia provides protection from sensorimotor and cognitive behavioral deficits. J Neurotrauma. 1995;12:289-98.

24. Dixon CE, Markgraf CG, Angileri F, et al. Protective effects of moderate hypothermia on behavioral deficits but not necrotic cavitation following cortical impact injury in the rat. J Neurotrauma. 1998;15:95-103.

25. Robertson CL, Clark RS, Dixon CE, et al. No long-term benefit from hypothermia after severe traumatic brain injury with secondary insult in rats [In Process Citation]. Crit Care Med. 2000;28:3218-23.

26. Jacobs $S$, Hunt R, Tarnow-Mordi W, Inder T, Davis P. Cooling for newborns with hypoxic ischaemic encephalopathy. Cochrane Database Syst Rev. 2007;17, CD003311.

27. Polderman KH. Induced hypothermia and fever control for prevention and treatment of neurological injuries. Lancet. 2008;371:1955-69.

28. Nunnally ME, Jaeschke R, Bellingan GJ, et al. Targeted temperature management in critical care: a report and recommendations from five professional societies. Crit Care Med. 2011;39:1113-25.
29. Biggart MJ, Bohn DJ. Effect of hypothermia and cardiac arrest on outcome of near-drowning accidents in children. J Pediatr. 1990;117:179-83.

$30 . \bullet$ Hutchison JS, Ward RE, Lacroix J, et al. Hypothermia therapy after traumatic brain injury in children. $\mathrm{N}$ Engl J Med. 2008;358:2447-56.

This multicenter study found that hypothermia, while effective at reducing ICP in pediatric severe TBI patients, frequently led to rebound $\mathrm{ICH}$, and did not confer a functional or mortality benefit at 6 months post injury versus normothermia.

31.• Adelson PD, Ragheb J, Kanev P, et al. Phase II clinical trial of moderate hypothermia after severe traumatic brain injury in children. Neurosurgery. 2005;56:74054. discussion -54 .

This phase II multicenter RCT reported that hypothermia for $48 \mathrm{~h}$ reduced ICP while also leading to rebound ICH on rewarming in some patients. Study was stopped early for futility for primary outcome.

32.• Nielsen N, Wetterslev J, Cronberg T, et al. Targeted temperature management at 33 degrees $\mathrm{C}$ versus 36 degrees $\mathrm{C}$ after cardiac arrest. N Engl J Med. 2013;369:2197-206.

RCT of hypothermia versus controlled normothermia in adults comatose after out of hospital cardiac arrest with presumed cardiac etiology that found no benefit of hypothermia for favorable outcome.

33. Moler FW. Planning therapeutic hypothermia after pediatric cardiac arrest trial. Crit Care Med. 2006;34:A421.

34. Polderman KH. Application of therapeutic hypothermia in the intensive care unit. Opportunities and pitfalls of a promising treatment modality-Part 2: Practical aspects and side effects. Intensive Care Med. 2004;30:757-69.

35. Bembea M, Nadkarni V, Diener-West M, et al. Temperature patterns in the early post-resuscitation period after pediatric in-hospital cardiac arrest. PCCM 2010;in press.

36. Siebke H, Rod T, Breivik H. Survival after 40 minutes submersion without cerebral sequelae. Lancet. 1975;1:1275-7.

37. Conn AW, Edmonds JE, Barker GA. Cerebral resuscitation in near drowning. Pediatr Clin N Am. 1979;26:691.

38. Bernard SA, Gray TW, Buist MD, et al. Treatment of comatose survivors of out-of-hospital cardiac arrest with induced hypothermia. N Engl J Med. 2002;346:557-63.

39. Hypothermia after Cardiac Arrest Study Group. Mild therapeutic hypothermia to improve the neurologic outcome after cardiac arrest. N Engl J Med. 2002;346:549-56.

40. Gluckman PD, Wyatt JS, Azzopardi D, et al. Selective head cooling with mild systemic hypothermia after neonatal encephalopathy: multicentre randomised trial. Lancet. 2005;365:663-70.

41. Shankaran S, Laptook AR, Ehrenkranz RA, et al. Wholebody hypothermia for neonates with hypoxic-ischemic encephalopathy. N Engl J Med. 2005;353:1574-84. 
42. Peberdy MA, Callaway CW, Neumar RW, et al. Part 9: post-cardiac arrest care: 2010 American heart association guidelines for cardiopulmonary resuscitation and emergency cardiovascular care. Circulation.

2010;122:S768-86.

43. Fink EL, Clark RS, Kochanek PM, Bell MJ, Watson RS. A tertiary care center's experience with therapeutic hypothermia after pediatric cardiac arrest. Pediatr Crit Care Med. 2010;11:66-74.

Single center retrospective analysis of the use of unprotocolized hypothermia in pediatric cardiac arrest patients with detailed data on patients and adverse events.

44. Doherty DR, Parshuram CS, Gaboury I, et al. Hypothermia therapy after pediatric cardiac arrest. Circulation. 2009;119:1492-500.

Multicenter observational study of unprotocolized hypothermia that showed clinician use of hypothermia focused on sicker patients.

45. Scholefield B, Duncan H, Davies P, et al. Hypothermia for neuroprotection in children after cardiopulmonary arrest. Cochrane Database Syst Rev. 2013;2, CD009442.

46. Fink EL, Kochanek PM, Clark RS, Bell MJ. How I cool children in neurocritical care. Neurocrit Care. 2010;12:414-20.

47. Fink EL, Kochanek PM, Clark RS, Bell MJ. Fever control and application of hypothermia using intravenous cold saline. Pediatr Crit Care Med. 2012;13:80-4.

48. Patterson JL, Carapetian SA, Hageman JR, Kelley KR. Febrile seizures. Pediatr Ann. 2013;42:249-54.

49. Baulac S, Gourfinkel-An I, Nabbout R, et al. Fever, genes, and epilepsy. Lancet Neurol. 2004;3:421-30.

50. Swinyard EA, Toman JE. Effects of alterations in body temperature on properties of convulsive seizures in rats. Am J Physiol. 1948;154:207-10.

51. Vastola EF, Homan R, Rosen A. Inhibition of focal seizures by moderate hypothermia. A clinical and experimental study. Arch Neurol. 1969;20:430-9.

52. Yang XF, Rothman SM. Focal cooling rapidly terminates experimental neocortical seizures. Ann Neurol. 2001;49:721-6.

53. Schiff SJ, Somjen GG. The effects of temperature on synaptic transmission in hippocampal tissue slices. Brain Res. 1985;345:279-84.

54. Shen KF, Schwartzkroin PA. Effects of temperature alterations on population and cellular activities in hippocampal slices from mature and immature rabbit. Brain Res. 1988;475:305-16.

55. Thompson SM, Masukawa LM, Prince DA. Temperature dependence of intrinsic membrane properties and synaptic potentials in hippocampal CA1 neurons in vitro. J Neurosci. 1985;5:817-24.

56. Volgushev M, Vidyasagar TR, Chistiakova M, Yousef T, Eysel UT. Membrane properties and spike generation in rat visual cortical cells during reversible cooling. J Physiol. 2000;522(Pt 1):59-76.

57. Aihara H, Okada Y, Tamaki N. The effects of cooling and rewarming on the neuronal activity of pyramidal neurons in guinea pig hippocampal slices. Brain Res. 2001;893:36-45.

58. Oztas B, Kaya M. The effect of profound hypothermia on blood-brain barrier permeability during pentylenetetrazol-induced seizures. Epilepsy Res. 1994;19:221-7.

59. Corry JJ, Dhar R, Murphy T, Diringer MN. Hypothermia for refractory status epilepticus. Neurocrit Care 2008.

60. Elting JW, Naalt J, Fock JM. Mild hypothermia for refractory focal status epilepticus in an infant with hemimegalencephaly. Eur J Paediatr Neurol. 2010;14:452-5.

Case report in which targeted temperature management was used to prevent seizures in an infant.

61. Orlowski JP, Erenberg G, Lueders H, Cruse RP. Hypothermia and barbiturate coma for refractory status epilepticus. Crit Care Med. 1984;12:367-72.

62.• Guilliams K, Rosen M, Buttram S, et al. Hypothermia for pediatric refractory status epilepticus. Epilepsia. 2013;54:1586-94.

Largest pediatric case series reporting experience with hypothermia in the setting of refractory status epilepticus.

63. Shein SL, Reynolds TQ, Gedela S, Kochanek PM, Bell MJ. Therapeutic hypothermia for refractory status epilepticus in a child with malignant migrating partial seizures of infancy and SCN1A mutation: a case report. Ther Hypothermia Temp Manag. 2012;2:144-9.

Case report demonstrating the utility of hypothermia to suppress status epilepticus and loss of effect with return to normothermia in a child.

64. Brophy GM, Bell R, Claassen J, et al. Guidelines for the evaluation and management of status epilepticus. Neurocrit Care. 2012;17:3-23.

65. Abend NS, Dlugos DJ. Treatment of refractory status epilepticus: literature review and a proposed protocol. Pediatr Neurol. 2008;38:377-90.

66. Wilkes R, Tasker RC. Pediatric intensive care treatment of uncontrolled status epilepticus. Crit Care Clin. 2013;29:239-57.

67. Sanchez Fernandez I, Abend NS, Agadi S, et al. Gaps and opportunities in refractory status epilepticus research in children: a multi-center approach by the Pediatric Status Epilepticus Research Group (pSERG). Seizure. 2014;23:87-97.

68. Dietrich WD, Alonso O, Halley M, Busto R. Delayed posttraumatic brain hyperthermia worsens outcome after fluid percussion brain injury: A light and electron microscopic study in rats. Neurosurgery. 1996;38:53341.

69. Thompson HJ, Tkacs NC, Saatman KE, Raghupathi R, McIntosh TK. Hyperthermia following traumatic brain injury: a critical evaluation. Neurobiol Dis. 2003; 12:163-73.

70. Li J, Jiang JY. Chinese head trauma data bank: effect of hyperthermia on the outcome of acute head trauma patients. J Neurotrauma. 2012;29:96-100.

71. Ginsberg MD, Sternau LL, Globus MY-T, Dietrich WD, Busto R. Therapeutic modulation of brain temperature: 
Relevance to ischemic brain injury. Cerebrovasc Brain Metab Rev. 1992;4:189-225.

72. Dietrich WD, Alonso O, Busto R, Globus MY-T, Ginsberg MD. Post-traumatic brain hypothermia reduces histopathological damage following concussive brain injury in the rat. Acta Neuropathol. 1994;87:250-8.

73. Wagner AK, Bayir H, Ren D, Puccio A, Zafonte RD, Kochanek PM. Relationships between cerebrospinal fluid markers of excitotoxicity, ischemia, and oxidative damage after severe TBI: the impact of gender, age, and hypothermia. J Neurotrauma. 2004;21:125-36.

74. Ji X, Luo Y, Ling F, et al. Mild hypothermia diminishes oxidative DNA damage and pro-death signaling events after cerebral ischemia: a mechanism for neuroprotection. Front Biosci. 2007;12:1737-47.

75. Bayir H, Adelson PD, Wisniewski SR, et al. Therapeutic hypothermia preserves antioxidant defenses after severe traumatic brain injury in infants and children. Crit Care Med. 2009;37:689-95.

76. Biswas AK, Bruce DA, Sklar FH, Bokovoy JL, Sommerauer JF. Treatment of acute traumatic brain injury in children with moderate hypothermia improves intracranial hypertension. Crit Care Med. 2002;30:2742-51.

First RCT of HT vs. normothermia for treatment of intracranial hypertension after severe TBI.

77.• Adelson PD, Wisniewski SR, Beca J, et al. Comparison of hypothermia and normothermia after severe traumatic brain injury in children (Cool Kids): a phase 3, randomised controlled trial. Lancet Neurol. 2013; 12:546-53.

The multicenter phase III RCT comparing HT versus controlled normothermia in pediatric severe TBI was stopped early for futility.

78. Ichiyama T, Suenaga N, Kajimoto M, et al. Serum and CSF levels of cytokines in acute encephalopathy following prolonged febrile seizures. Brain Dev. 2008;30:47-52.

79. Kawano G, Iwata O, Iwata S, et al. Determinants of outcomes following acute child encephalopathy and encephalitis: pivotal effect of early and delayed cooling. Arch Dis Child. 2011;96:936-41.

An observational study that showed early initiation of therapeutic hypothermia improved neurologic outcomes, while delayed hypothermia may be harmful in children with encephalitis.

80. Vargas WS, Merchant S, Solomon G. Favorable outcomes in acute necrotizing encephalopathy in a child treated with hypothermia. Pediatr Neurol. 2012;46:387-9.

81. Ichikawa K, Motoi H, Oyama Y, Watanabe Y, Takeshita $\mathrm{S}$. Fulminant form of acute disseminated encephalomyelitis in a child treated with mild hypothermia. Pediatr Int. 2013;55:e149-51.

82.• Mourvillier B, Tubach F, van de Beek D, et al. Induced hypothermia in severe bacterial meningitis: a randomized clinical trial. JAMA. 2013;310:2174-83.

RCT in adults with bacterial meningitis that showed no benefit to using hypothermia in improving outcomes and a signal for potential harm versus normothermia.

83. Chaudhuri A, Martinez-Martin P, Kennedy PG, et al. EFNS guideline on the management of communityacquired bacterial meningitis: report of an EFNS Task Force on acute bacterial meningitis in older children and adults. Eur J Neurol. 2008;15:649-59.

84. Kneen R, Michael BD, Menson E, et al. Management of suspected viral encephalitis in children - Association of British Neurologists and British Paediatric Allergy, Immunology and Infection Group national guidelines. J Infect. 2012;64:449-77.

85. Tunkel AR, Hartman BJ, Kaplan SL, et al. Practice guidelines for the management of bacterial meningitis. Clin Infect Dis. 2004;39:1267-84. 